\title{
Lewis Acid Catalyzed Rearrangement of Furylcarbinols: The Aza- and Oxa- Piancatelli Cascade Reaction
}

\author{
Leoni I. Palmer, Javier Read de Alaniz* \\ Department of Chemistry and Biochemistry, University of California-Santa Barbara, Santa Barbara, CA 93106-9510, USA \\ Fax+1(805)8934120; E-mail: javier@chem.ucsb.edu \\ Received: 30.08.2013; Accepted: 24.09.2013
}

\begin{abstract}
The acid-catalyzed rearrangement of furylcarbinols is utilized to access 4,5-substituted cyclopentenones. This cascade transformation began with implementing anilines, as an alternative nucleophile to water as used in the Piancatelli rearrangement, and has currently progressed through an intramolecular rearrangement to the use of alcohols as the nucleophile.
\end{abstract}

Key words: lanthanides, cascade, rearrangement, cyclopentenones, $4 \pi$ electrocyclization

The replacement of a multistep chemical synthesis with a cascade reaction is a powerful strategy to improve the efficiency and sustainability of synthesis. ${ }^{1}$ The potential of a cascade transformation is maximized when combined with straightforward reaction conditions and the formation of widely utilized synthetic building blocks. Incorporating pericyclic reactions within cascade transformations is an interesting subset of this research area; here the benefits are combined with the ability to create new carboncarbon bonds stereospecifically by simple orbital reorganization.

While a number of important methodologies involving cascade reactions have been developed, we saw the work of Piancatelli and others on the acid-catalyzed rearrangement of furylcarbinols and furfural to be an amazing transformation with, as we felt, room for further expansion in developing its synthetic utility. Herein, we describe the evolution and most efficient strategies employed for these cascade rearrangements and highlight our recent contributions to this area.

In 1976, Piancatelli and co-workers developed the synthesis of 4-hydroxycyclopentenone derivatives by an acidcatalyzed rearrangement of 2-furylcarbinols (Scheme 1, b). ${ }^{2}$ Despite being discovered over 35 years ago, the Piancatelli reaction still provides the most direct synthetic route to 4-hydroxycyclopentenones and has been the foundation for the synthesis of numerous prostaglandins and other biologically active molecules. ${ }^{3}$ Recent advances in the Piancatelli rearrangement include the development of microwave-assisted conversions of furfural, which dramatically increases the rate and often leads to high yields. ${ }^{4}$

SYNLETT 2014, 25, 0008-0011

Advanced online publication: 06.11.2013

DOI: 10.1055/s-0033-1340157; Art ID: ST-2013-P0838-SP

(C) Georg Thieme Verlag Stuttgart · New York
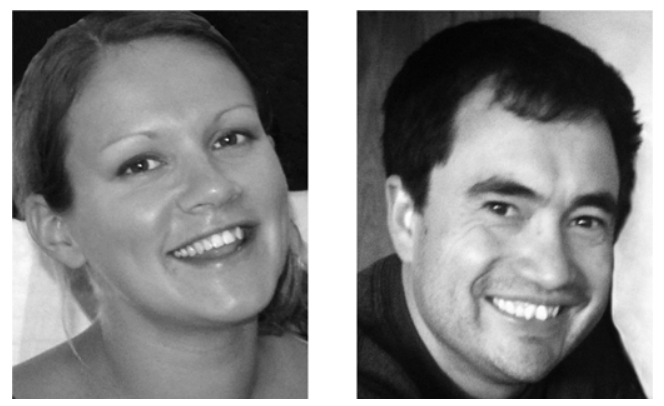

Javier Read de Alaniz joined the department of Chemistry and Biochemistry at UC, Santa Barbara in 2009 as an Assistant Professor. He received his B.S. degree from Fort Lewis College (Durango, Colorado) in 1999 where he conducted undergraduate research under the direction of Professor William R. Bartlett. He obtained his Ph.D. under the supervision of Professor Tomislav Rovis at Colorado State University in 2006 with a research focus on asymmetric catalysis. Javier then moved to California, where he worked in the area of total synthesis with Professor Larry E. Overman at the University of California, Irvine.

Leoni Palmer chose to read chemistry at the University of Durham and after completing a year in industry at Pfizer, Kent, she graduated with a Masters in 2006. She then moved to study at Nottingham University under Professor Christopher J. Moody to obtain her PhD in 2010 in the area of total synthesis before moving to her current position at UCSB as a Postdoctoral Scholar in the Read de Alaniz Group.

Piancatelli proposed a mechanistic hypothesis that resembles closely the Nazarov reaction (Scheme 1 , a). ${ }^{5}$ In a Nazarov reaction, a divinyl ketone (1) is transformed to a cyclopentenone (2) in acidic media via a concerted ring closure of a pentadienyl cation (A) to a hydroxycyclopentyl cation (B). In the Piancatelli rearrangement (Scheme 1, b), in the presence of acidic media the furylcarbinol (3) forms a highly reactive oxocarbenium ion, which upon attack by a suitable nucleophile, in this case water, and subsequent ring opening forms a cyclopentadienyl cation $(\mathbf{C})$. Analogous to the Nazarov reaction, this cyclopentadienyl cation can proceed through a $4 \pi$-electrocyclic ring closure to give the desired cyclopentenone product (4). De Lera has studied this transformation computationally and determined that the rearrangement probably proceeds through the proposed concerted electrocyclic process and not through an alternative mechanism like an intramolecular aldol reaction or a Prins reaction. ${ }^{6}$

A year after Piancatelli's discovery, studies by Lewis and co-workers demonstrated that 4,5-diaminocyclopentenones $(\mathbf{5})$ could be formed from furfural through a related cascade rearrangement, albeit in moderate yield. ${ }^{7}$ In 2007 , 


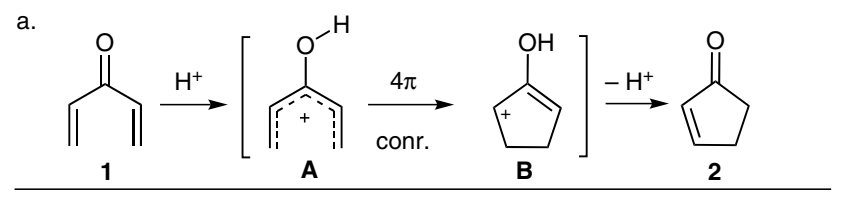

b.

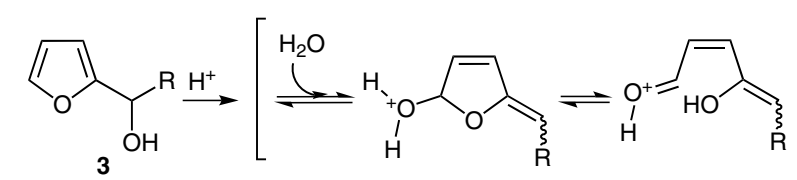

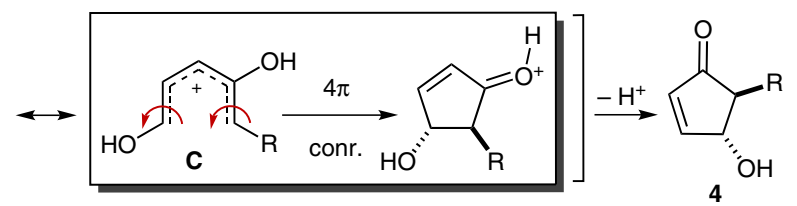

Scheme 1 Mechanistic proposed similarity of Nazarov (a) to Piancatelli (b) $4 \pi$ electrocyclizations

$\mathrm{Li}$ and Batey rendered the cascade condensation/ringopening/electrocyclization process practical and synthetically useful by using lanthanide(III) catalysis (Scheme 2). ${ }^{8}$

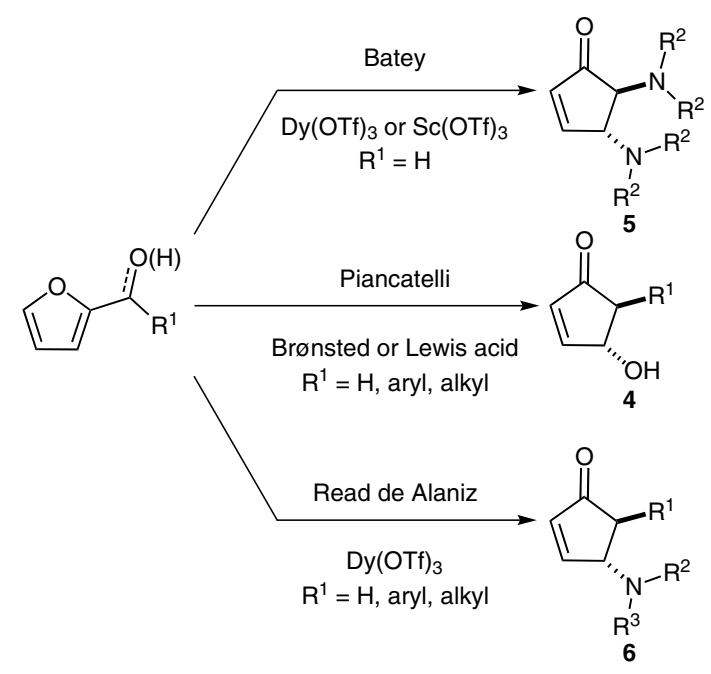

Scheme 2 Acid-catalyzed rearrangements of furfural

Our motivation for the development of the aza-Piancatelli rearrangement resulted from a literature survey that revealed a lack of methods available for the direct synthesis of 4-aminocyclopentenones. All prior reported methods require multiple steps and typically lack substitution at the adjacent 5-position. ${ }^{9}$ We hypothesized that an efficient, catalytic aza-Piancatelli rearrangement could serve as a powerful method to streamline the synthesis of biological and medicinal molecules, specifically those bearing nitrogen functionality.

Our investigations began, encouraged by Batey's use of rare-earth Lewis acids to access bis 4,5-diaminocyclopentenones, with the use of $\mathrm{Dy}(\mathrm{OTf})_{3}$ in catalytic amounts $(5$ $\mathrm{mol} \%$ ) to facilitate the rearrangement of furylcarbinols with aniline nucleophiles (Scheme 3). To our delight, the rearrangement was efficient, trans-selective and amenable to a wide range of substitutions both on the aniline and on the furylcarbinol. ${ }^{10} \mathrm{We}$ were most encouraged by this initial study, that demonstrates that electron-rich, electron-poor, sterically bulky and even secondary anilines (16) participate successfully in the rearrangement (Scheme 3). Subsequent to our initial report, Reddy et al. and Wang et al. independently demonstrated that phosphomolybdic acid (PMA), In(OTf $)_{3}$ and $\mathrm{La}(\mathrm{OTf})_{3}$ could also be used to catalyze the aza-Piancatelli reaction. ${ }^{11}$

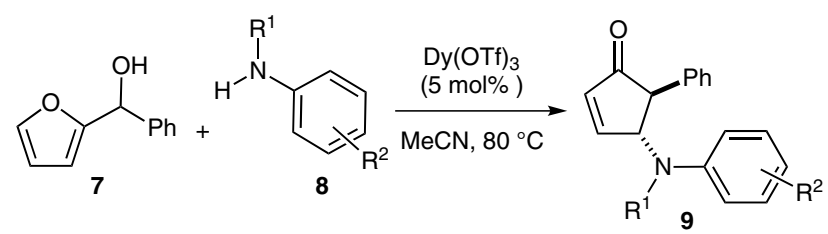<smiles>[R]c1ccc(NC2C=CC(=O)C2c2ccccc2)cc1</smiles>

$10 \mathrm{R}=\mathrm{H}, 86 \%$

$11 \mathrm{R}=\mathrm{I}, 92 \%$

$12 \mathrm{R}=\mathrm{OMe}, 62 \%$ $13 \mathrm{R}=\mathrm{CO}_{2} \mathrm{Me}, 86 \%$

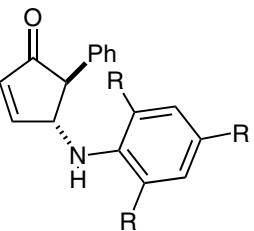

$14 \mathrm{R}=\mathrm{Me}, 91 \%$ $15 R=F, 74 \%$<smiles>Cc1ccc2c(c1)CCCN2[C@@H]1C=CC(=O)C1c1ccccc1</smiles>

$1674 \%$

Scheme 3 The intermolecular aza-Piancatelli reaction

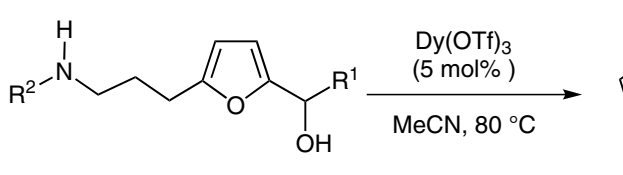
17<smiles>[10BH][13CH]1[10BH]C2(C=CC(=O)C2)CC1</smiles><smiles>[R]c1ccc(N2CCCC23C=CC(=O)C3c2ccccc2)cc1</smiles><smiles>O=C1C=CC2(CCCN2c2ccccc2)C1c1ccc(P)cc1</smiles>

$22 \mathrm{R}=\mathrm{NO}_{2}, 67 \%$ $23 \mathrm{R}=\mathrm{OMe}, 81 \%$ $24 \mathrm{R}=\mathrm{Br}, 84 \%$<smiles>[R]C1C(=O)C=CC12CCCN2c1ccccc1</smiles>

$25 \mathrm{R}=\mathrm{Me}, 91 \%$

$26 \mathrm{R}=\mathrm{Bu}, 97 \%$

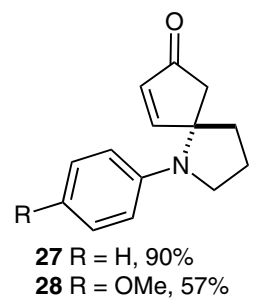

Scheme 4 The intramolecular aza-Piancatelli reaction

Desiring to progress the newly developed aza-Piancatelli rearrangement, a natural advance was to investigate the use of intramolecular substrates (Scheme 4), which met with an equally satisfactory level of success. Methods to construct azaspirocycles usually approach the two main challenges of their synthesis in discrete steps; construction of the $3^{\circ}$ carbon center bearing a nitrogen atom and 
the formation of the spirocyclic ring system. ${ }^{12}$ Here, we were most pleased to discover that we can combine these into a single transformation. ${ }^{13}$ Utilizing our previously determined conditions, we saw again that variation of substituents on both the aniline and furylcarbinol portions were well tolerated. Noteworthy was the inclusion of examples that had no substituent on the furylcarbinol (27 and 28; Scheme 4).

We saw fit to apply our cascade rearrangement methodology for the synthesis of biological and medicinal molecules. A structure-activity relationship (SAR) study by Merck revealed 1,2-trans-2,3-trans-cyclopentane-based scaffolds (30) to be comparable to FDA-approved hNK1 antagonist Aprepitant, used as an antiemetic for chemotherapy-induced nausea and vomiting. ${ }^{14} \mathrm{We}$ demonstrated that only four steps from our cyclopentenone product (29, formed in $60 \%$ yield on gram scale; Scheme 5) gave access to one such analogue in good yield with the option to easily access other derivatives if desired (30).

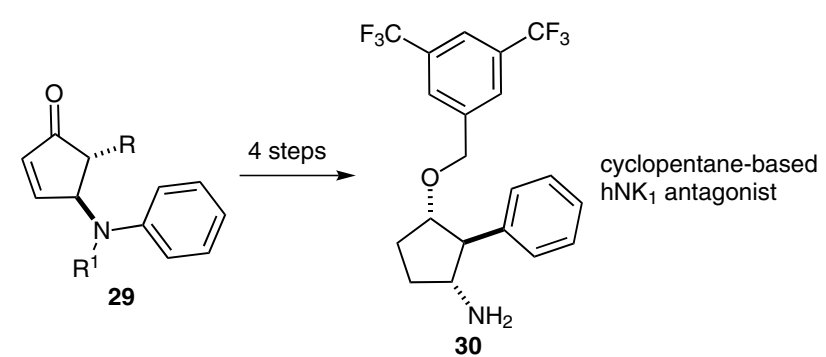

Scheme 5 Synthesis of an $\mathrm{hNK}_{1}$ antagonist

Spurred on by this success, we were keen to apply our methodology to an approach to the cephalotaxus alkaloid family of natural products. Pleasingly, rearrangement of the elaborate furylcarbinol (31) proceeded in excellent yield to give spirocyclic cyclopentenone (32; Scheme 6). Unfortunately, progression of this particular synthetic strategy was cut short due to difficulties in removing the

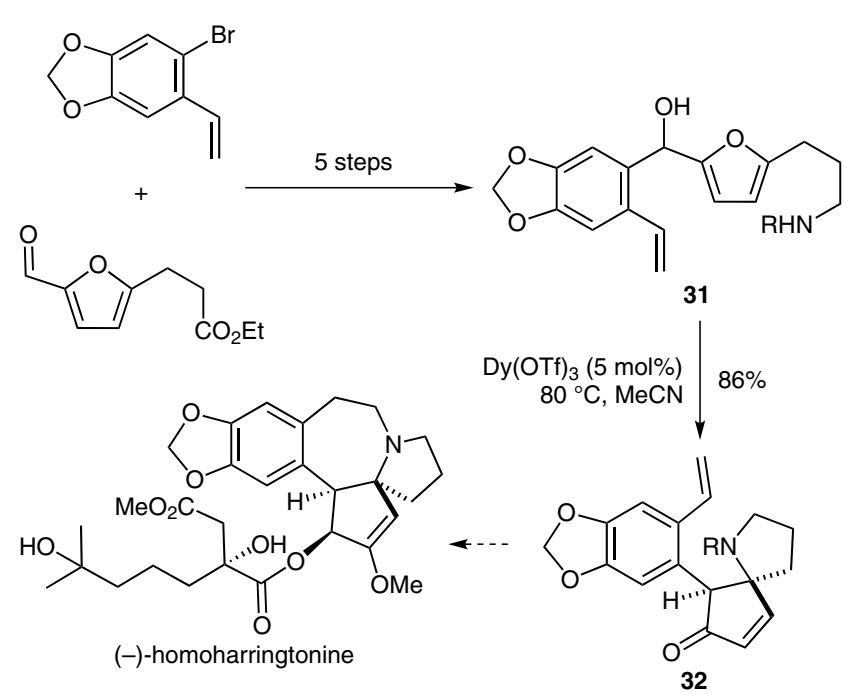

Scheme 6 Application to natural product synthesis $p$-methoxyphenyl group from the amine functionality without decomposition of the spirocyclic framework. ${ }^{15}$

Based on our success with the aza-Piancatelli rearrangement, we sought the use of alcohols as nucleophiles. ${ }^{16}$ Prior to our report, there were no examples of an oxaPiancatelli reaction. Here, we built substrates that had varying substitutions of the furylcarbinol (Scheme 7) as well as including the use of tethers containing primary, secondary and tertiary alcohols. The transferral of reaction conditions to the oxa-variant was not as straightforward as that between the inter- to intramolecular azaPiancatelli. This was not surprising as $\mathrm{Wu}$ et al. had extensively studied the chemistry of furylcarbinols similar to $\mathbf{3 3}$ and reported their use for the synthesis of oxabicyclic cyclopentenones and spiroketal enol ether derivatives. ${ }^{17}$ Despite the need for extensive optimization we discovered that solvent choice was critical. Use of solvents other than toluene led to decomposition of starting materials without any conversion to products. Once optimized conditions were identified, the scope of the oxa-Piancatelli reaction turned out to be broad.

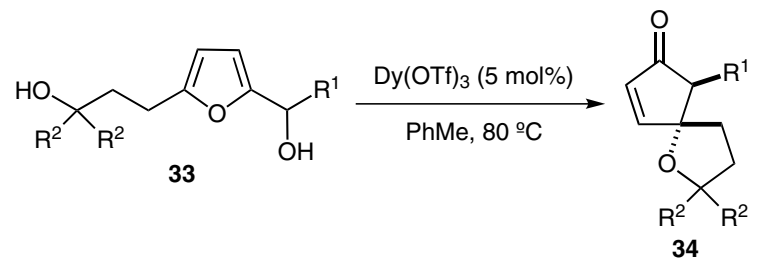

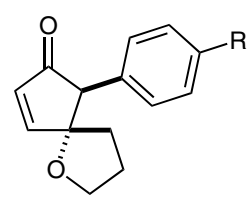

$35 \mathrm{R}=\mathrm{H}, 91 \%$

$36 \mathrm{R}=\mathrm{OMe}, 89 \%$

$37 \mathrm{R}=\mathrm{CF}_{3}, 88 \%$

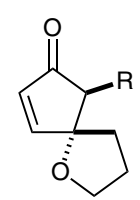

$38 \mathrm{R}=$ mesityl, $78 \%$ $39 \mathrm{R}=2$-naphthyl, $86 \%$
(

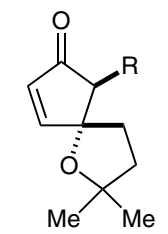

$40 \mathrm{R}=\mathrm{Ph}, 74 \%$

$41 \mathrm{R}=\mathrm{Bu}, 98 \%$

$42 \mathrm{R}=i-\mathrm{Pr}, 25 \%$
Scheme 7 The oxa-Piancatelli reaction

Over the course of these studies it became apparent to us that we were in a position to evaluate the mechanistic possibility that spirocyclic ethers could be a precursor to the more thermodynamically stable oxabicyclic cyclopentenones. ${ }^{17 \mathrm{c}, \mathrm{d}} \mathrm{We}$ decided to further investigate this relationship and were delighted to find that oxaspirocyclic cyclopentenone framework could be used to access fused oxa-bicycles (Scheme 8). ${ }^{18}$ Treatment of oxaspirocycles (43) with Amberlyst ${ }^{\circledR} 15$ in heated toluene resulted in clean conversion to fused cyclopentenones (44). This is a general transformation utilizing an acid-facilitated skeletal rearrangement to the thermodynamic product.

In summary, the Piancatelli rearrangement has been extended to include nitrogen nucleophiles and other oxygen nucleophiles in the synthesis of highly stereoselective and variably substituted cyclopentenones. We have demonstrated a transformation of value to the synthetic community for use in the construction of cyclopentenones, 


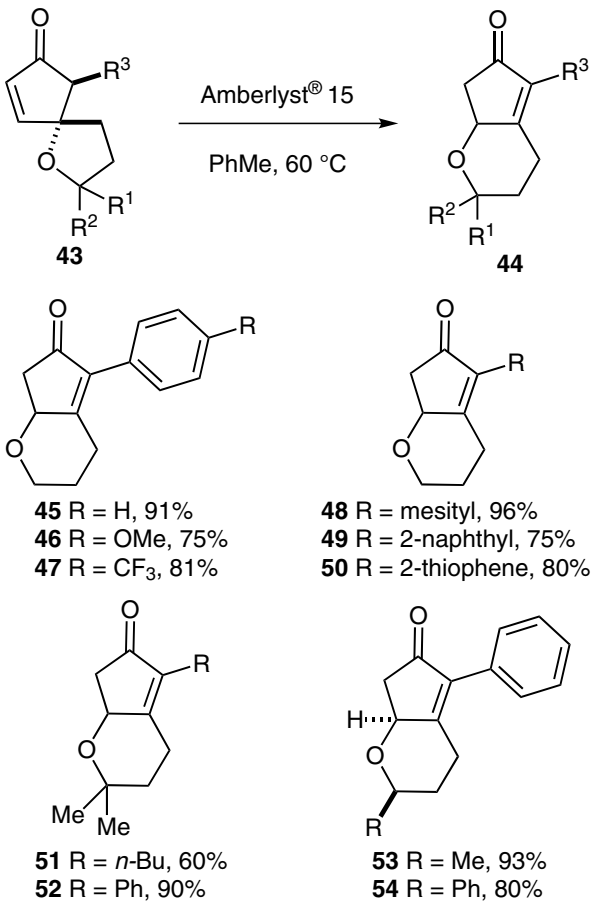

Scheme 8 Conversion of spirocycles into fused bicycles

spirocycles and fused bicyclic frameworks and promises to deliver further exciting developments in the future.

\section{Acknowledgment}

This work was supported by UCSB and NSF (CAREER Award CHE-1057180). Additional support was kindly provided by Eli Lilly (New Faculty Award to J.R.A.).

\section{References and Notes}

(1) For reviews on cascade transformations, see: (a) Tietze, L. F. Chem. Rev. 1996, 96, 115. (b) Tietze, L. F.; Rackelmann, N. Pure Appl. Chem. 2004, 76, 1967. (c) Wasilke, J.-C.; Obrey, S. J.; Baker, R. T.; Bazan, G. C. Chem. Rev. 2005, 105, 1001. (d) Sunderhaus, J. D.; Martin, S. F. Chem. Eur. J. 2009, 15, 1300.

(2) Piancatelli, G.; Scettri, A.; Barbadoro, S. Tetrahedron Lett. 1976, 17, 3555 .

(3) Piancatelli, G.; Dauria, M.; Donofrio, F. Synthesis 1994, 867.

(4) Ulbrich, K.; Kreitmeier, P.; Reiser, O. Synlett 2010, 2037.

(5) For recent reviews of the Nazarov and Pauson-Khand reactions, see: (a) Tius, M. A. Eur. J. Org. Chem. 2005, 2193. (b) Pellissier, H. Tetrahedron 2005, 61, 6479.

(c) Frontier, A. J.; Collison, C. Tetrahedron 2005, 61, 7577. (d) Grant, T. N.; Rieder, C. J.; West, F. G. Chem. Commun. 2009, 5676. (e) Spencer, W. T. III.; Vaidya, T.; Frontier, A. J. Eur. J. Org. Chem. 2013, 3621. (f) Blanco-Urgoiti, J.; Anorbe, L.; Perez-Serrano, L.; Dominguez, G.; Perez-
Castells, J. Chem. Soc. Rev. 2004, 33, 32. (g) Gibson, S. E.; Mainolfi, N. Angew. Chem. Int. Ed. 2005, 44, 3022; Angew. Chem. 2005, 117, 3082.

(6) (a) Faza, O. N.; López, C. S.; Álvarez, R.; de Lera, A. R. Chem. Eur. J. 2004, 10, 4324. (b) Davis, R. L.; Tantillo, D. J. Curr. Org. Chem. 2010, 14, 1561.

(7) Lewis, K. G.; Mulquiney, C. E. Aust. J. Chem. 1979, 32, 1079.

(8) Li, S. W.; Batey, R. A. Chem. Commun. 2007, 3759.

(9) For select examples, see: (a) Davis, F. A.; Wu, Y. Z. Org. Lett. 2004, 6, 1269. (b) Dauvergne, J.; Happe, A. M.; Jadhav, V.; Justice, D.; Matos, M. C.; McCormack, P. J.; Pitts, M. R.; Roberts, S. M.; Singh, S. K.; Snape, T. J.; Whittall, J. Tetrahedron 2004, 60, 2559. (c) Dauvergne, J.; Happe, A. M.; Roberts, S. M. Tetrahedron 2004, 60, 2551. (d) Zaja, M.; Blechert, S. Tetrahedron 2004, 60, 9629.

(10) Veits, G. K.; Wenz, D. R.; Read de Alaniz, J. Angew. Chem. Int. Ed. 2010, 49, 9484.

(11) For other developments in the aza-Piancatelli reaction, see: (a) Subba Reddy, B. V.; Reddy, Y. V.; Lakshumma, P. S.; Narasimhulu, G.; Yadav, J. S.; Sridhar, B.; Reddy, P. P.; Kunwar, A. C. RSC $A d v$. 2012, 2, 10661. (b) Liu, J.; Shen, Q.; Yu, J.; Zhu, M.; Han, J.; Wang, L. A. Eur. J. Org. Chem. 2012, 6933. (c) Subba Reddy, B. V.; Narasimhulu, G.; Subba Lakshumma, P.; Vikram Reddy, Y.; Yadav, J. S. Tetrahedron Lett. 2012, 53, 1776.

(12) (a) For a review on azaspirocycles, see: Dake, G. Tetrahedron 2006, 62, 3467. For select examples, see: (b) Wipf, P.; Stephenson, C. R. J.; Walczak, M. A. A. Org. Lett. 2004, 6, 3009. (c) Burkhard, J. A.; Wagner, B.; Fischer, H.; Schuler, F.; Muller, K.; Carreira, E. M. Angew. Chem. Int. Ed. 2010, 49, 3524; Angew. Chem. 2010, 122, 3603.

(d) Tanner, D.; Hagberg, L. Tetrahedron 1998, 54, 7907.

(e) Wardrop, D. J.; Basak, A. Org. Lett. 2001, 3, 1053.

(f) Brummond, K. M.; Lu, J. Org. Lett. 2001, 3, 1347.

(g) Fenster, M. L. D. B.; Patrick, B. O.; Dake, G. R. Org. Lett. 2001, 3, 2109. (h) Abe, H.; Aoyagi, S.; Kibayashi, C. J. Am. Chem. Soc. 2005, 127, 1473.

(13) Palmer, L. I.; Read de Alaniz, J. Angew. Chem. Int. Ed. 2011, $50,7167$.

(14) (a) Finke, P. E.; Meurer, L. C.; Levorse, D. A.; Mills, S. G.; MacCoss, M.; Sadowski, S.; Cascieri, M. A.; Tsao, K.-L.; Chicchi, G. G.; Metzger, J. M.; MacIntyre, D. E. Bioorg. Med. Chem. Lett. 2006, 16, 4497. (b) Meurer, L. C.; Finke, P. E.; Owens, K. A.; Tsou, N. N.; Ball, R. G.; Mills, S. G.; MacCoss, M.; Sadowski, S.; Cascieri, M. A.; Tsao, K.-L.; Chicchi, G. G.; Egger, L. A.; Luell, S.; Metzger, J. M.; MacIntyre, D. E.; Rupniak, N. M. J.; Williams, A. R.; Hargreaves, R. J. Bioorg. Med. Chem. Lett. 2006, 16, 4504.

(15) Previously undisclosed results.

(16) Palmer, L. I.; Read de Alaniz, J. Org. Lett. 2013, 15, 476.

(17) For select studies, see: (a) Yin, B.-L.; Yang, Z.-M.; Hu, T.-S.; Wu, Y.-L. Synthesis 2003, 1995. (b) Chen, L.; Xu, H.-H.; Yin, B.-L.; Xiao, C.; Hu, T.-S.; Wu, Y.-L. J. Agric. Food. Chem. 2004, 52, 6719. (c) Yin, B.-L.; Wu, Y.-K.; Wu, Y.-L. J. Chem. Soc., Perkin Trans. 1 2002, 1746. (d) Yin, B.-L.; Wu, Y.-L.; Lai, J.-Q. Eur. J. Org. Chem. 2009, 2695.

(18) Palmer, L. I.; Veits, G. K.; Read de Alaniz, J. Eur. J. Org. Chem. 2013, 6237. 